\title{
Introduction of the George Eric Lamming Memorial Lecture
}

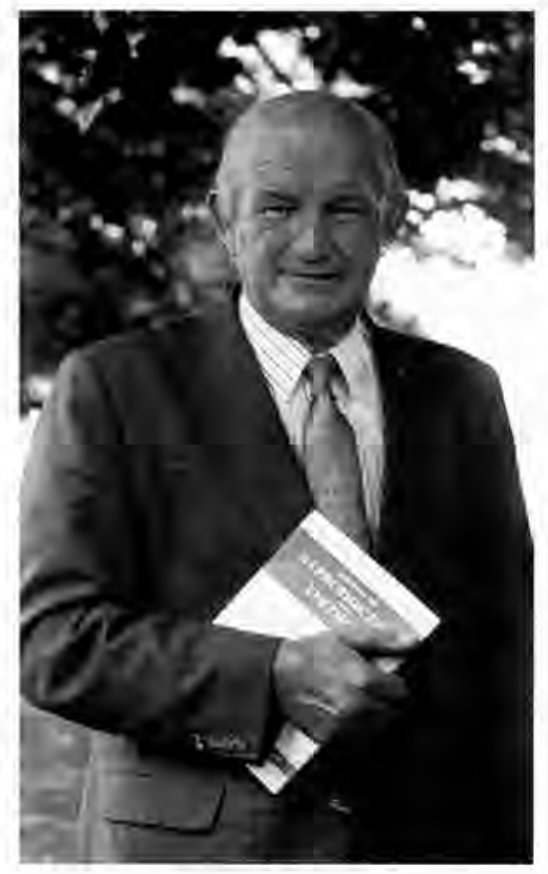

The work presented by Dr. William Murdoch today includes a sequence of carefully designed investigations into the ovulatory process and is a fitting tribute to the career of Eric Lamming. Although best known for his work on anabolic agents in reproduction and his pioneering studies of the use of progesterone in milk to diagnose reproductive status in the dairy cow, Dr. Lamming was a student of broader aspects of ovarian function in ruminants. Much of his work was related to regulation of luteal function, but he contributed papers relating to follicles, including roles of the gonadotropins in induction of ovulation, and feed effects on ovulation rate.

George Eric Lamming was born in Swallow, Lincolnshire on April 14, 1927. He earned his B. Sc. in dairying from Nottingham University, and then an M. Sc. in agricultural economics and a Ph. D. in reproductive physiology at the University of Illinois. His doctoral dissertation was on the effects of vitamin A deficiency in the rabbit.

He returned to Britain in 1951, joining Sir John Hammond's laboratory at Cambridge, and then moved back to Sutton Bonington in 1953. He progressed from Lecturer to Senior Lecturer during 1953 to 1964 , and served as Professor of Animal Physiology from 1964 through 1992, then continued his laboratory in reproduction as Professor Emeritus. He played a major part in building an international reputation for Sutton Bonington as a premier School of Agriculture at the University of Nottingham.

As this series of Symposia on Reproduction in Domestic Ruminants developed, Dr. Lamming was one of the forces behind expansion of the breadth of coverage beyond the sheep and cow. His broad interests in the areas of nutrition, growth and reproduction, and the endocrinology of reproduction led him to challenge many students over the years. Quoting from his obituary, "Eric Lamming was a man of powerful intellect and strong personality who made important contributions to research on animal fertility and reproduction, and to the application of that research to veterinary and farming practice."

The work that Dr. Murdoch presents today is important in contexts other than ruminant reproduction. First, it represents the type of studies in animals that can attract support from sources related to human health in an era when support for agricultural animal research has declined severely. Second, it has provided possible insight into a devastating disease that has touched many of our lives. Dr. William Hansel, who was presented with the Upjohn Lifetime Achievement Award at an earlier symposium in this series at Colorado Springs, lost his beloved wife, Millbury, to ovarian cancer. He has devoted his research to this disease in recent years. I personally lost a vibrant young cousin, Cathy Bowyer, not yet 50 years of age, to ovarian cancer in 2009. 
Dr. Murdoch earned his B. S. at Delaware Valley College in 1975, and his M. S. in 1977 and Ph. D. in 1980 from West Virginia University. He has carried out his academic career at the University of Wyoming. It gives me great pleasure to introduce Professor William J. Murdoch to present this year's Lamming Memorial Lecture.

Keith Inskeep, Division of Animal and Nutritional Sciences, West Virginia University 